\title{
Resveratrol ameliorates high-glucose-induced hyperpermeability mediated by caveolae via VEGF/KDR pathway
}

\author{
Chong Tian $\cdot$ Rui Zhang $\cdot$ Xiaolei Ye $\cdot$ \\ Changhui Zhang $\cdot$ Xin Jin $\cdot$ Yukio Yamori $\cdot$ \\ Liping Hao $\cdot$ Xiufa Sun $\cdot$ Chenjiang Ying
}

Received: 11 April 2012/Accepted: 28 August 2012/Published online: 16 September 2012

(C) Springer-Verlag 2012

\begin{abstract}
Endothelial hyperpermeability induced by hyperglycemia is the initial step in the development of atherosclerosis, one of the most serious cardiovascular complications in diabetes. In the present study, we investigated the effects of resveratrol (RSV), a bioactive ingredient extracted from Chinese herb rhizoma polygonum cuspidatum, on permeability in vitro and the molecular mechanisms involved. Permeability was assessed by the efflux of fluorescein isothiocyanate (FITC)-dextran permeated through the monolayer endothelial cells (ECs). The mRNA levels, protein expressions, and secretions were measured by quantitative real-time PCR, western blot, and ELISA, respectively. Increased permeability and caveolin1 (cav-1) expression were observed in monolayer ECs exposed to high glucose. Resveratrol treatment alleviated the hyperpermeability and the overexpression of cav-1
\end{abstract}

C. Tian $\cdot$ R. Zhang $\cdot$ C. Zhang $\cdot$ X. Jin $\cdot$ L. Hao $\cdot$ X. Sun

C. Ying $(\square)$

Department of Nutrition and Food Hygiene,

School of Public Health, Tongji Medical College,

Huazhong University of Science and Technology,

Wuhan 430030, People's Republic of China

e-mail: yingchenjiang@yahoo.com

X. Ye

Department of Public Health, Wenzhou Medical College,

Wenzhou 325035, People's Republic of China

Y. Yamori

Institute for World Health Development, Mukogawa Women's

University, Nishinomiya 663-8179, Japan

Present Address:

C. Ying

Department of Nutrition and Food Hygiene, School of Public

Health, Huazhong University of Science and Technology,

Wuhan 430030, People's Republic of China induced by high glucose in a dose-dependent manner. $\beta$-Cyclodextrin, a structural inhibitor of caveolae, reduced the hyperpermeability caused by high glucose. Resveratrol also down-regulated the increased expressions of vascular endothelial growth factor (VEGF) and kinase insert domain receptor (KDR, or VEGF receptor-2) induced by high glucose. Inhibition of VEGF/KDR pathway by using SU5416, a selective inhibitor of KDR, alleviated the hyperpermeability and the cav-1 overexpression induced by high glucose. The above results demonstrate that RSV ameliorates caveolae-mediated hyperpermeability induced by high glucose via VEGF/KDR pathway.

Keywords Resveratrol - Diabetes - Atherosclerosis . Hyperpermeability · Caveolae · VEGF

\section{Introduction}

Atherosclerosis, one of the most serious cardiovascular complications of diabetes mellitus, occurs primarily in coronary arteries, lower extremities and extracranial carotid arteries. Retention or accumulation of modified macromolecules like lipoproteins and advanced glycation end products (AGE) in the subendothelial space is an initial event in the formation of atherosclerosis; however, the underlying mechanisms are not fully understood.

Hyperpermeability, the increased transport of large molecules including AGE and lipoproteins to the subendothelial space is the early response of ECs to insults such as hyperglycemia or dyslipidemia (Simionescu 2007). Caveolae, referring to the 50-100 nm sized, flask-shaped, and non-clathrin-coated invaginations of the plasma membrane, regulates the kinetics of vesicle transport. Caveolae-mediated permeability plays a major role in the 
transport of large molecules across endothelium (Komarova and Malik 2010). It was reported that LDL-derived cholesterol, the major component of atherosclerotic plaque, enters the subendothelial space through the caveolaemediated pathway (Sun et al. 2010). Results from cav-1 (caveolin-1, the key structural protein of caveolae)-deficient mice indicated that cav-1 in endothelium is essential in the translocation of LDL-derived cholesterol into the vessel wall and in the development of atherosclerosis, and this result was further confirmed in apoE-/- mice (Fernandez-Hernando et al. 2009, 2010). On the other side, vascular endothelial growth factor (VEGF), one of the strongest hyperpermeability inducers (Senger et al. 1990), plays a critical role in both physiological and pathological hyperpermeability (Bates and Harper 2002). Overexpression of VEGF was found in the progression of nephritic and ophthalmic complications in diabetes (Kim et al. 2000; Cukiernik et al. 2004). The molecular mechanism involved in the permeability alteration induced by VEGF in diabetic condition is not clear; however, there are evidences indicating that caveolae was indispensable to the process, and it was suggested that VEGF-induced permeability was mediated by caveolae (Feng et al. 1999). Report showed that VEGF increased the permeability through caveolaemediated transcellular pathway in the blood-tumor barrier (Zhao et al. 2011). In addition, kinase insert domain receptor (KDR, or VEGF receptor-2), a receptor of VEGF that is considered mediating most of the known cellular responses (permeability included) to VEGF, locates in caveolae (Holmes et al. 2007).

Resveratrol (3,5,4'-trihydroxy-trans-stilbene, RSV), a kind of dietary polyphenol abundantly existed in red wine and Chinese herb rhizoma polygonum cuspidatum, might play an important role in 'French paradox' (Kopp 1998). It was reported there was an adverse link between moderate drinking of red wine and risk of heart disease (Szmitko and Verma 2005), and further the anti-atherosclerosis effect of RSV had been found (Fan et al. 2008). It was shown that RSV ameliorated the increased permeability in pulmonary artery ECs induced by side-stream cigarette smoke (Low et al. 2007). Lin reported that RSV protects against oxidized LDL-induced breakage of the blood-brain barrier (Lin et al. 2010). Limited evidence showed that RSV regulates VEGF level in vascular ECs; however, decreased VEGF level caused by RSV treatment was observed in gingival fibroblasts (Nunez et al. 2010), retinal cells (Dugas et al. 2010), tongue squamous cell carcinoma, and hepatoma cells (Zhang et al. 2005). Based on these data, we hypothesized that RSV may regulate high-glucoseinduced hyperpermeability via VEGF pathway.

In all, however, the role of caveolae and VEGF in the development of atherosclerosis in diabetes and the underlying mechanisms of permeability change remain unclear.
We here observed the effect of RSV on hyperpermeability induced by high glucose in monolayer aortic ECs and investigated the role of VEGF and caveolae.

\section{Methods}

Reagents and materials

Primary bovine aortic endothelial cells (BAECs) were purchased from Health Science Research Resources Bank (Osaka, Japan, no. C-003-5C). Dulbecco's Modified Eagle's Medium (DMEM) and fetal bovine serum (FBS) were purchased from Gibco Inc. (Grand Island, NY, USA). Twenty-four-well filtration microplate and FITC-dextran (40 kDa, anionic) were from Whatman Polyfiltronics (Whatman Inc, Clifton, NJ, USA) and Molecular Probes, Inc. (Eugene, OR, USA), respectively. Bovine VEGF ELISA Kit was from RB International Inc. (Monrovia, CA, USA); anti-KDR antibody (ab2349) was purchased from Abcam Inc. (Cambridge, UK). Anti- $\beta$-actin antibody (H-196) and anti-cav-1 antibody (sc894) were from Santa Cruz Biotechnology, Inc. (Santa Cruz, CA, USA). RSV was purchased from NanJing ZheLang Inc. (NanJing, JiangSu, China); TRIZOL was from Invitrogen Inc. (Carlsbad, CA, USA), and quantitative real-time PCR kit was purchased from TAKARA Bio Inc. (Dalian, LiaoNing, China). SU5416 was purchased from Sigma-Aldrich China Inc. (Shanghai, China).

\section{Cell culture and treatments}

Primary BAECs were maintained in DMEM containing $10 \% \mathrm{FBS}$ at $37{ }^{\circ} \mathrm{C}$ in $5 \% \mathrm{CO}_{2}$ as described previously (Ying et al. 2003). Six treatment groups plus one control group were included in the study; treatments were as follows: confluent cells incubated with $33 \mathrm{mmol} / \mathrm{L}$ glucose were treated with different concentrations of RSV $(0,0.1$, $1,10 \mu \mathrm{mol} / \mathrm{L}, 72 \mathrm{~h}), \beta$-cyclodextrin $(8 \mu \mathrm{mol} / \mathrm{L}, 30 \mathrm{~min})$, or SU5416 $(10 \mu \mathrm{mol} / \mathrm{L}, 1 \mathrm{~h})$, respectively. Confluent cells incubated with $5.5 \mathrm{mmol} / \mathrm{L}$ glucose in medium were used as control group.

\section{Cell permeability assay}

Fluorescent intensity of FITC-dextran that passes through the confluent cell layer to the lower chamber was used to demonstrate the permeability. Cell permeability assay was performed as previously described (Hordijk et al. 1999). Briefly, BAECs were seeded in the upper chambers of $0.4-\mu \mathrm{m}$ polycarbonate transwell filters of a 24-well filtration microplate. When BAECs were grown to confluence, the medium was replaced with fresh phenol red-free 
DMEM. After incubation as described above, FITCdextran $(1 \mathrm{mg} / \mathrm{ml})$ was incubated with the cells for $1 \mathrm{~h}$, then the filtration microplate was removed, and the fluorescence in the medium of the feeder tray was evaluated by a multiple-mode microplate reader (Biotech, highland park, USA) at $494 \mathrm{~nm}$ excitation and $521 \mathrm{~nm}$ emission. The procedure was performed in triplicate and repeated once.

\section{Quantitative RT-PCR}

The mRNA expression levels of VEGF, KDR, and Cav-1 were analyzed with qRT-PCR. Briefly, total RNA was extracted by TRIZOL according to the manufacturer's instructions and quantified by UV spectrophotometry; samples with the value of A260/280 between 1.8 and 2.0 were used. Reverse transcription reaction (RT) was performed with $1 \mu \mathrm{g}$ total RNA from each sample using random primers. Real-time PCR analysis was carried out using QPCR SYBR Green mix with the following parameters: 1 cycle, $95^{\circ} \mathrm{C}, 5 \mathrm{~s} ; 40$ cycles, $95^{\circ} \mathrm{C} 10 \mathrm{~s}, 57^{\circ} \mathrm{C}$, $30 \mathrm{~s}$. Changes of gene expression were determined by the comparative $\mathrm{Ct}$ method with GADPH as reference. The primers used in the PCR were as follows: glyceraldehyde3-phosphate dehydrogenase (GAPDH), sense: TAC AAG CCC AACAAC AAG G, antisense: ACA GTG AAG GTG GTG AAG C; VEGF, sense: GGC TGC TGT AAT GAC GAA, antisense: TCC TAT GTG CTG GCT TTG; KDR, sense: ATG GGA ACC GAA ACC TA, antisense: CCT GGG CAC CTT CTA CT; Caveolin-1, sense: CTA TGG CAG AGG AAA TGA A, antisense: ACA GTG AAG GTG GTG AAG C. Six replicate samples were analyzed in each group.

\section{Enzyme-linked immunosorbent assay}

Secreted VEGF was analyzed with ELISA. An enzymelinked immunosorbent assay was strictly according to the manufacturer's instruction. Briefly, culture supernatants were harvested, centrifuged to eliminate the impurities, and then incubated in the plate precoated with anti-bovine VEGF antibody at $37{ }^{\circ} \mathrm{C}$ for $30 \mathrm{~min}$. HRP-conjugated reagent was added and the mixture was incubated at $37{ }^{\circ} \mathrm{C}$ for $30 \mathrm{~min}$, and after washing, the chromogen solutions $\mathrm{A}$ and $\mathrm{B}$ were added in sequence followed by incubation at $37{ }^{\circ} \mathrm{C}$ in dark for $15 \mathrm{~min}$. At last, the reaction was stopped and the absorbance was read at $450 \mathrm{~nm}$ within $10 \mathrm{~min}$. Measurement was performed in six replicates. The result was presented as ng/L.

Electrophoresis and immunoblotting

The expression levels of KDR and cav-1 protein were analyzed using Western blot. Whole cell extracts were prepared as previously described (Ying et al. 2003). Briefly, the cells were lysed in the extraction buffer containing $50 \mathrm{mmol} / \mathrm{L}$ Tris/HCl (pH 8.0), $150 \mathrm{mmol} / \mathrm{L} \mathrm{NaCl}$, $1 \%$ Nonidet-P40, $1 \%$ sodium deoxycholate, $0.1 \%$ sodium dodecyl sulfate (SDS), $0.1 \mathrm{mmol} / \mathrm{L}$ DTT, $0.05 \mathrm{mmol} / \mathrm{L}$ PMSF, $0.002 \mathrm{mg} / \mathrm{ml}$ aprotinin, $0.002 \mathrm{mg} / \mathrm{ml}$ leupeptin, and $1 \mathrm{mmol} / \mathrm{L} \mathrm{NaVO} 3$ after stimulation. The protein concentration was quantified with BIO-RAD Dc protein assay reagent. Equal amounts of extracted proteins were separated by SDS-PAGE and transferred to polyvinylidene fluoride (PVDF) membrane (Millipore, Billerica, Massachusetts, USA). Proteins were visualized using an enhanced chemiluminescence Western blotting luminal reagent (Amersham Biosciences, Little Chalfont, UK). Protein expression was visualized with a chemiluminescent detection system (Syngen, Cambridge, UK) and analyzed by Gel Pro 3.0 software (Biometra, Goettingen, Germany). Each experiment was repeated 3 times.

Statistical analysis

All quantitative data are presented as mean \pm SEM. Data were analyzed by ANOVA-SNK comparisons; $P<0.05$ was considered statistically significant.

\section{Results}

RSV down-regulated endothelial hyperpermeability induced by high glucose

Permeability of aortic endothelial monolayer cells was measured by the amount of efflux of FITC-dextran permeated through the monolayer ECs (Fig. 1). The fluorescence intensity in high glucose group was $2748 \pm 88$ fluorescent unit (FU), which was significantly higher than that of the control group (1990 \pm 38 FU). RSV treatment reduced the fluorescence intensity in a dose-dependent manner.

SU5416 and $\beta$-cyclodextrin down-regulated endothelial hyperpermeability

To test the role of VEGF in the hyperpermeability caused by high glucose, we blocked the VEGF pathway with SU5416 (10 $\mu \mathrm{mol} / \mathrm{L}, 1 \mathrm{~h})$ and found that SU5416 downregulated the permeable fluorescence significantly compared to the high glucose group (Fig. 2). Caveolae was reported to mediate macromolecule transportation. We inhibited caveolae-dependent endocytosis with $\beta$-cyclodextrin $(8 \mathrm{mmol} / \mathrm{L}, 30 \mathrm{~min})$. Compared to the high glucose group, $\beta$-cyclodextrin treatment significantly decreased the permeable fluorescence (Fig. 2). 
Fig. 1 Effects of RSV treatment on high-glucoseinduced hyperpermeability. The result was shown by the dextran that passes through the confluent cell layer to the lower chamber $(* P<0.05$ vs. the control; ${ }^{\#} P<.05$ vs. the HG group). Data are expressed as the mean $\pm \operatorname{SEM}(N=6)$ fluorescent intensity of FITC-

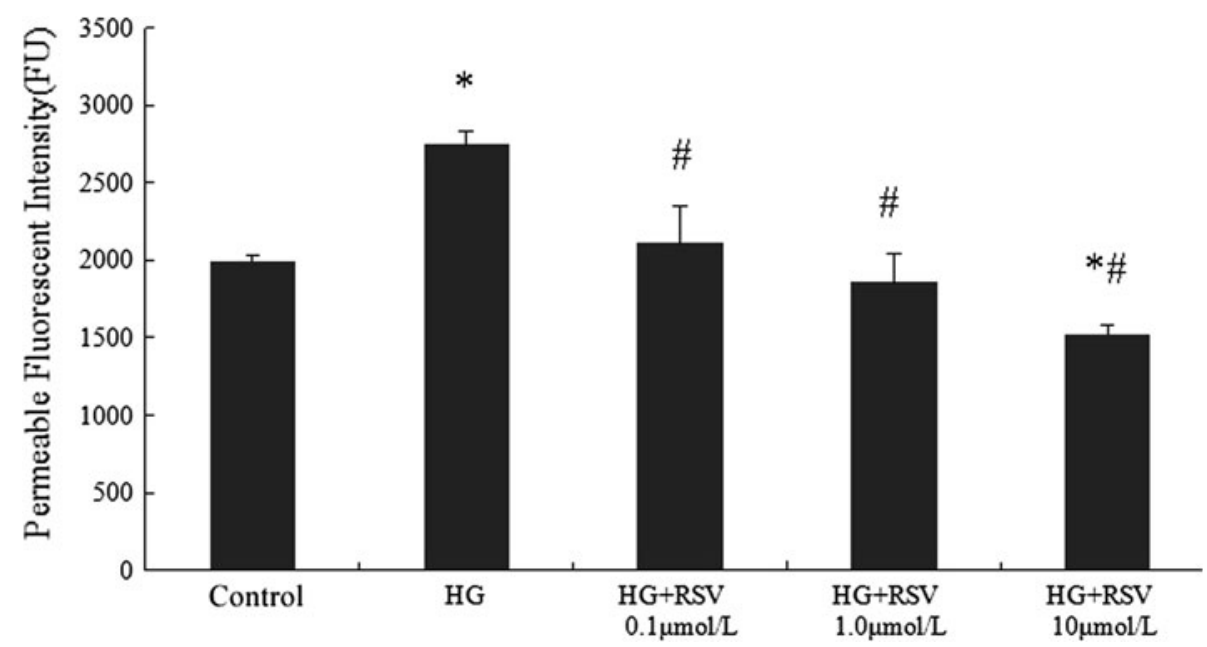

Fig. 2 Effects of

$\beta$-cyclodextrin and SU5416 on high-glucose-induced

hyperpermeability. Fluorescent intensity of FITC-dextran that passes through the confluent cell layer to the lower chamber was used to demonstrate the permeability $(* P<0.05$ vs. the control; ${ }^{\#} P<0.05$ vs. the HG group). Data are expressed as the mean $\pm \operatorname{SEM}(N=6)$

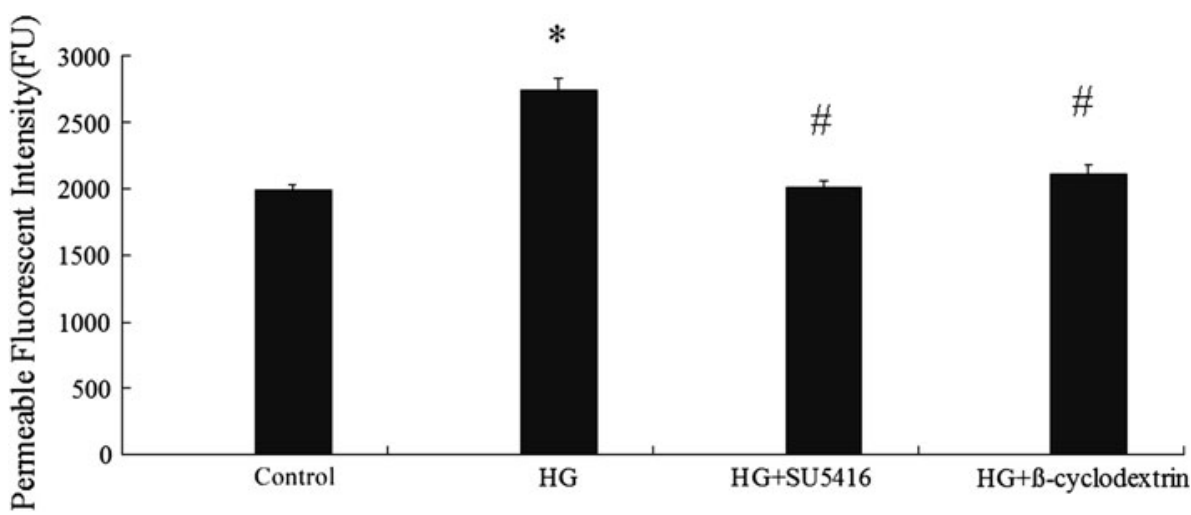

RSV down-regulated VEGF expression, KDR expressions, and VEGF secretion

VEGF mRNA under high glucose condition was significantly higher than that in control group, while co-incubation with RSV alleviated the increase in mRNA expression dose dependently (Fig. 3a). Besides the mRNA levels, high glucose incubation increased the VEGF secretion significantly, while the increase in secretion of VEGF was diminished in $\mathrm{HG}+\operatorname{RSV}(1,10 \mu \mathrm{mol} / \mathrm{L})$ groups (Fig. 3b), no difference was observed in VEGF secretion level between $0.1 \mu \mathrm{mol} / \mathrm{L}$ RSV group and the high glucose group.

High glucose incubation up-regulated both the mRNA (Fig. 4a) and protein expressions of KDR (Fig. 4b), while treatments with three different doses of RSV lessened the increased expression of KDR.

\section{RSV and SU5416 down-regulated cav-1 expressions}

As showed in Fig. 5, compared to the overexpression of cav-1 in high glucose group, RSV incubation down-regulated the protein expression significantly. Like the effect of RSV treatment, specific blocking of VEGF-KDR pathway by SU5416 down-regulated the cav-1 expression, which suggested that caveolae could be regulated by VEGF/KDR pathway.

\section{Discussion}

The present work demonstrated that high glucose caused hyperpermeability, which can be ameliorated by RSV treatment. RSV exhibited significant effects on expressions of VEGF/KDR and cav-1, and secretion of VEGF. Evidence from inhibitors indicated that VEGF/KDR and caveolae were responsible for high-glucose-induced hyperpermeability. Furthermore, blocking of VEGF/KDR pathway down-regulated cav-1 expression and ameliorated hyperpermeability.

The prevalence of diabetes has been increasing worldwide. Over 92 million adults with diabetes and 148 million prediabetic adults make China the country with largest diabetic population (Yang et al. 2010). Atherosclerosis is the most common and serious complications in diabetes and caused $80 \%$ of all deaths among diabetic patients (Webster and Scott 1997). Hyperglycemia is recognized as a major factor in the pathogenesis of atherosclerosis in diabetes (Laakso 1999). High glucose had been reported to 
Fig. 3 Effects of RSV treatment on high-glucoseinduced VEGF levels. Confluent cells were treated with different doses of RSV for $72 \mathrm{~h}$, respectively. The supernatant of cell culture medium was collected for ELISA testing of secreted VEGF. (a) The mRNA level of VEGF after incubation. Comparative $\mathrm{Ct}$ method with GADPH as reference was adopted. (b) The secreted amount of VEGF in supernatant of cell medium, the unit is $\mathrm{ng} / \mathrm{L}$. ( $P P<0.05$ vs. the control; ${ }^{\#} P<0.05$ vs. the HG group). Data are expressed as the mean $\pm \operatorname{SEM}(N=6)$
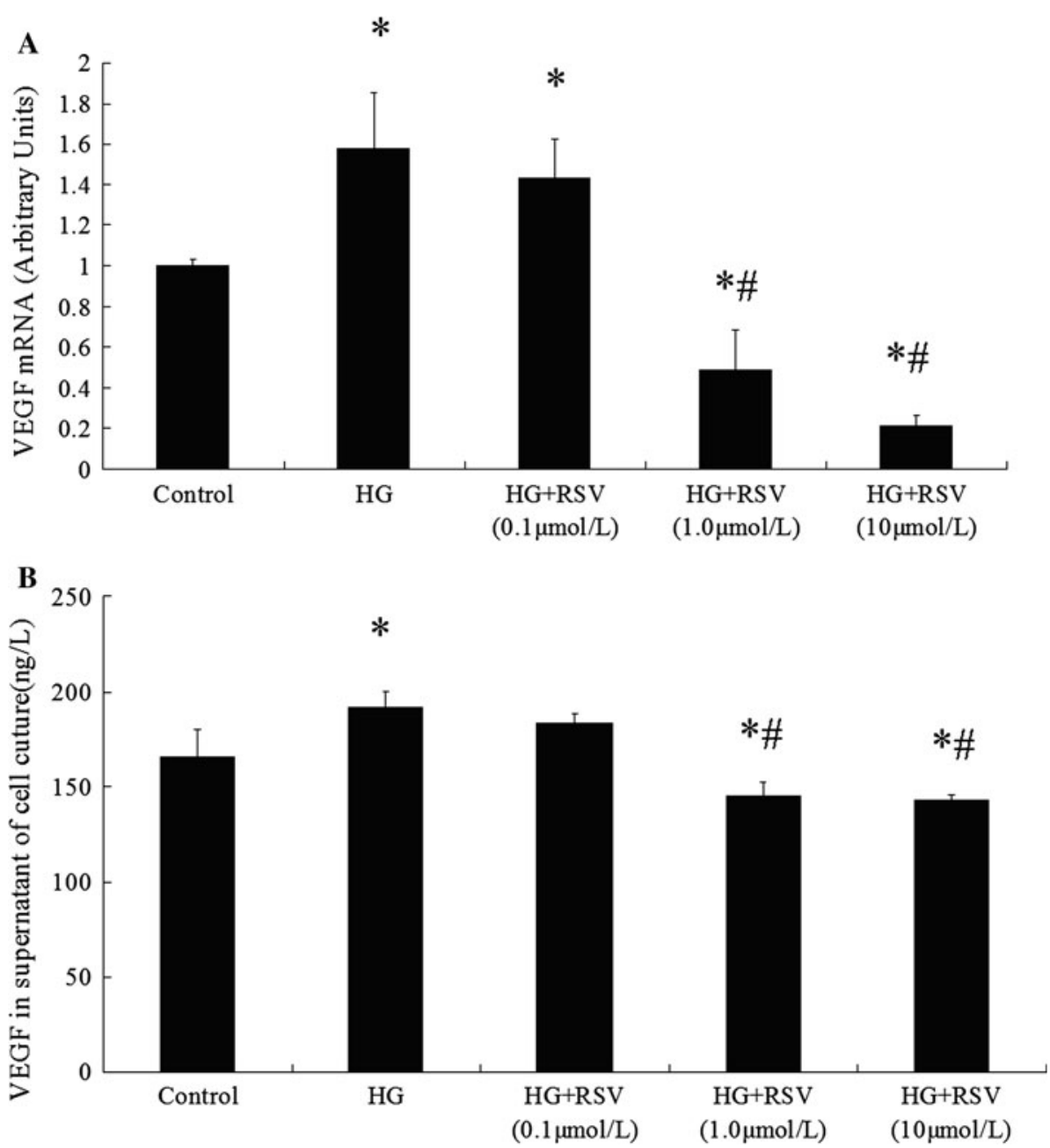

increase the permeability of ECs of umbilical vein (Dang et al. 2005) or micro-vessels (Scalia et al. 2007) in human. In the present study, high glucose incubation induced hyperpermeability in monolayer aortic ECs. Amelioration of the endothelial hyperpermeability under high glucose condition may exert a preventing effect in the initiation of diabetic athersclerotic complications. It is well established that RSV is associated with a reduced risk of cardiovascular diseases. Although its effect on endothelial hyperpermeability was rarely reported, RSV was shown to inhibit accumulation of fatty streak, the first grossly visible lesion in the development of atherosclerosis (Auger et al. 2005). In the present study, RSV co-incubation was observed to ameliorate the high-glucose-induced hyperpermeability in aortic endothelial monolayer cells. The RSV concentrations $(0.1,1$, and $10 \mu \mathrm{mol} / \mathrm{L})$ used in this study were in consistence with the estimated free RSV levels of human serum, 2.06 and $0.29 \mu \mathrm{mol} / \mathrm{L}$ in a $70-\mathrm{kg}$ man and woman, respectively (Zamora-Ros et al. 2008). The findings suggest that RSV from dietary intake may protect against high-glucose-induced hyperpermeability and be beneficial to the prevention of atherosclerotic complications of diabetes.

Caveolae, flask-shaped invaginations in the plasma membrane, were found to transport molecules from the lumen of the vessels to the subendothelial space in its original identification. Caveolae along with cav-1, the integral protein of caveolae, were recognized to be important in pathogenesis of atherosclerosis, in particular, the intimal LDL accumulation (Pavlides et al. 2012). Report showed that transportation of LDL and other macromolecules to the subendothelial space, the initial step of atherosclerosis, is mediated by caveolae (Gustafsson and Boren 2004). Furthermore, increased protein expression of cav-1 was reported in the aorta of diabetic rats (Elcioglu et al. 2010) and in the aorta of high-fat diet fed rats from our previous study (Yang et al. 2007). Cav-1 deficiency was reported to be associated with reduced atherosclerosis in apoE-/- mice (Frank et al. 2004). In the present study, increased hyperpermeability along with increased cav-1 expression was observed in high glucose incubated cells, which can be ameliorated by RSV co-treatment. And the 

treatment on high-glucoseinduced KDR expressions. After the treatment with different doses of RSV for $72 \mathrm{~h}$, respectively, the cells were detached and lysed for total RNA and protein extraction. Comparative $\mathrm{Ct}$ method with GADPH as reference was adopted to analyze the mRNA level of KDR (Fig. $4 \mathrm{a}, N=6$ ). The protein expression was expressed as arbitrary units using beta-actin as reference, with the value of the control group set to 1 (Fig. $3 \mathrm{~b}, N=3$ ). ( $P P<0.05$ vs. the control; ${ }^{\#} P<0.05$ vs. the HG group). Data are expressed as the mean \pm SEM
Fig. 4 Effects of RSV

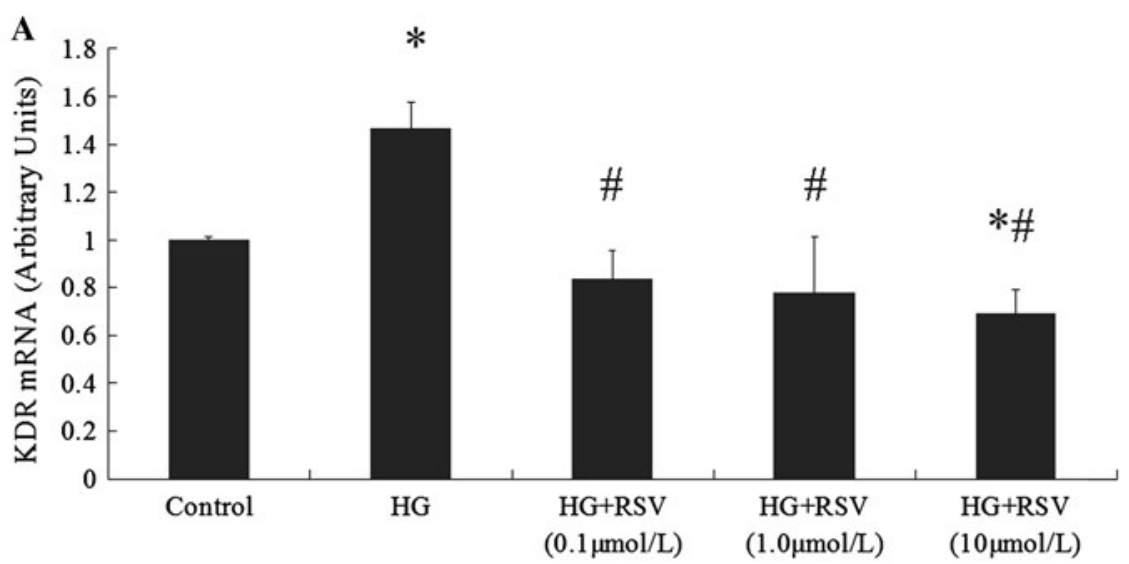

B
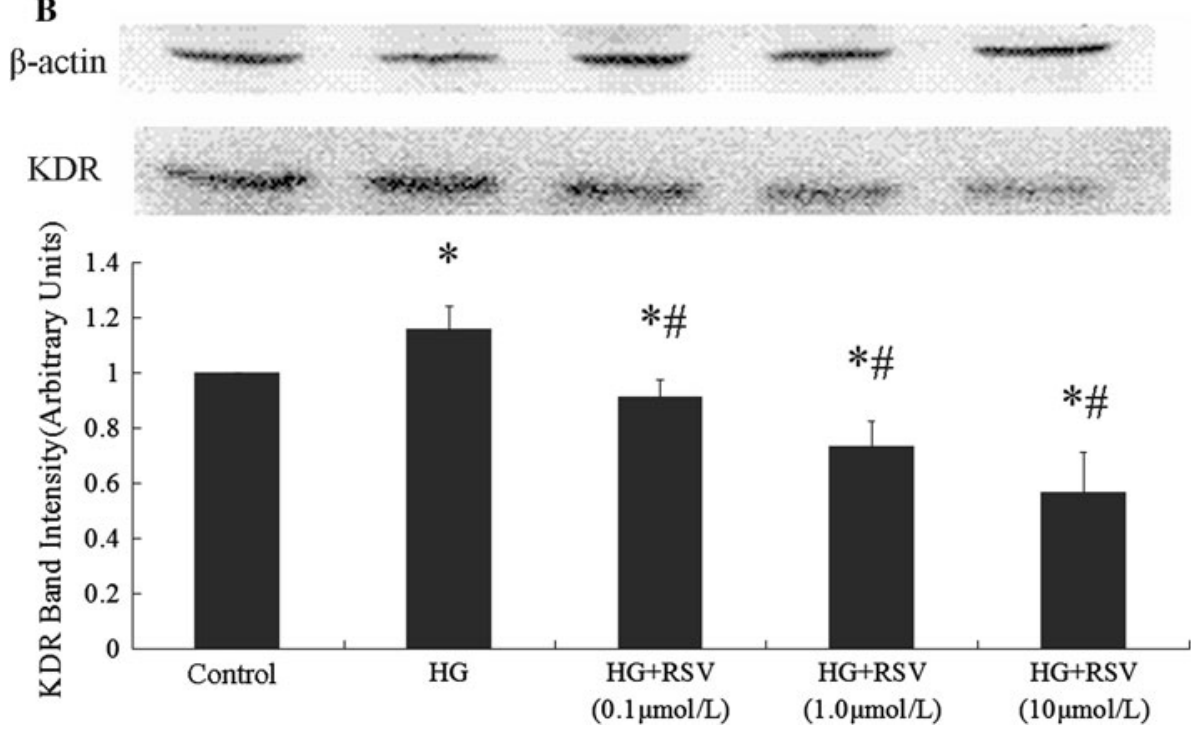

Fig. 5 Effects of RSV

treatment and SU5416 on highglucose-induced cav-1 expressions. The cells in high glucose condition were treated with different doses of RSV or SU5416, respectively. The protein expressions were detected. The result was expressed as arbitrary units using beta-actin as reference, with the value of the control group set to 1 (Fig. 5) $(* P<0.05$ vs. the control; ${ }^{\#} P<0.05$ vs. the HG group). Data are expressed as the mean $\pm \operatorname{SEM}(N=3)$ $\beta$-actin

Cav-1
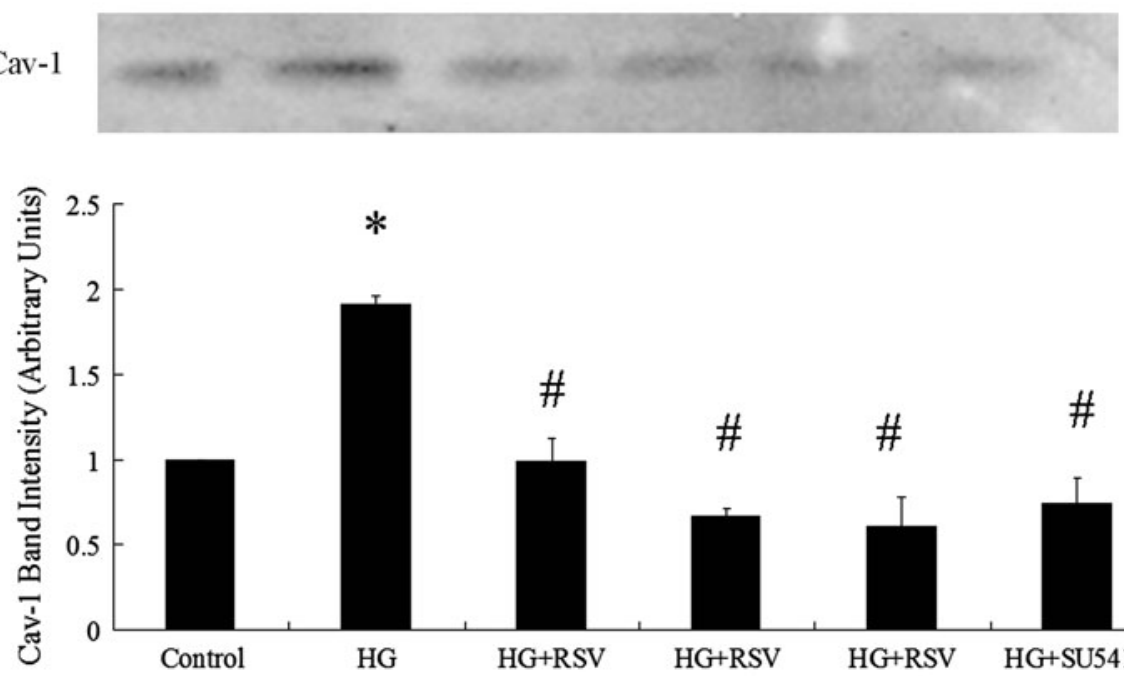

$*$
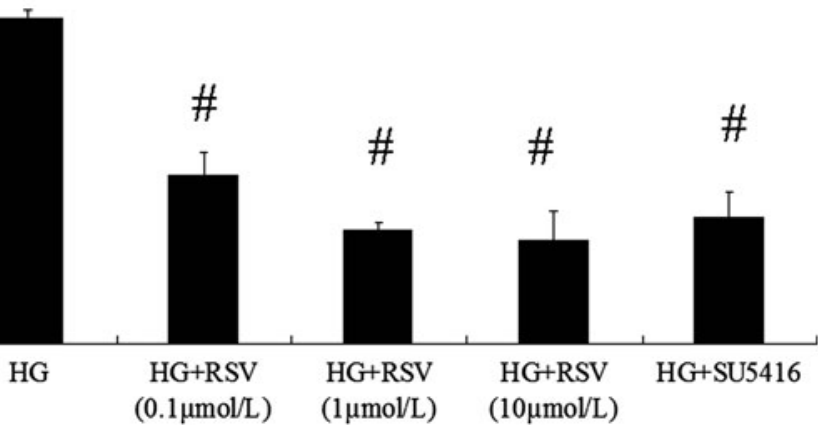
same effect was observed by inhibiting caveolae-dependent endocytosis with $\beta$-cyclodextrin. Caveolae, cholesteroland sphingolipid-rich smooth invaginations of the plasma membrane, are sensitive to cholesterol depletion. $\beta$-cyclodextrin can destroy caveolae structures (Parpal et al. 2001) by sequestering cholesterol in cultured cells (Klein et al. 1995). On the other side, Cav-1 is the key structural protein of caveolae (Drab et al. 2001). Reexpression of endothelial cav-1 in cav-/-mice demonstrated that cav-1 is indispensable to the transportation of LDL-derived cholesterol to the subendothelial space (Fernandez-Hernando et al. 2009). Further investigations using methods like morphological approaches would consolidate the conclusion.

VEGF, first identified as endothelial permeability factor, has been proved to induce hyperpermeability in vitro and in vivo. However, the mechanism of the hyperpermeability induced by VEGF is still inclusive. It was reported that VEGF increased paracellular permeability (DeMaio et al. 2004) and disrupted tight junction proteins claudin-5 (Argaw et al. 2009). Meanwhile transcellular transport by caveolae was shown to mediate the VEGF-induced endothelial permeability, and cav-1 was colocated with KDR (Feng et al. 1999; Zhao et al. 2011). VEGF induced the fission and fusion of caveolae, the increase in caveolae amount, and the increase in cav-1 expression (Chen et al. 2002). Methyl $\beta$-cyclodextrin treatment, which destroys the caveolae structure, prevented the transport of albumin, the most abundant protein in plasma (Minshall et al. 2000). As the inter-endothelial junction discontinuities are less than $3 \mathrm{~nm}$ and can only account for the passage of small molecules (Michel and Curry 1999), it was generally considered that macromolecules pass through the endothelium in transcellular way, most likely to be mediated by caveolae. Elevated plasma VEGF was observed in both diabetic patients with atherosclerosis and diabetic model of rabbit (Blann et al. 2002; Laakso 2008). In vitro studies demonstrated that high glucose induced VEGF in mesangial cells, glomerular podocytes, and retinal pigmented epithelial cells (Senger et al. 1990; Hoshi et al. 2002; Sone et al. 1996). Results in this study showed that high glucose incubation up-regulated VEGF and KDR expressions and increased VEGF secretions in aortic endothelial cells. Inhibition of the VEGF signaling pathway by selectively blocking of KDR down-regulated both the cav-1 expression and hyperpermeability under high glucose condition. The results indicated that VEGF/KDR pathway was responsible for high-glucose-induced hyperpermeability by regulating cav-1 expression. RSV was reported to downregulate VEGF in diabetes (Kim et al. 2012) and inhibit the VEGF-induced pro-arteriogenic effects in a hypercholesterolemic swine model (Chu et al. 2011). Another research showed that RSV exerted anti-angiogenic effect by downregulating KDR (Alex et al. 2010). Similar phenomenon was observed in the present study. Data show that RSV down-regulated the VEGF and KDR expressions, and VEGF secretions in cells cultured with high glucose. Furthermore, RSV also alleviated the cav-1 overexpression and hyperpermeability induced by high glucose. SU5416, selective inhibitor of KDR, resulted in same effects as RSV. Based on all above, RSV ameliorates macromolecular endothelial hyperpermeability induced by high glucose, and the amelioration is at least partially via the VEGF/KDR and caveolae pathway.

\section{Conclusions}

Our results showed that RSV alleviated the hyperpermeability induced by high glucose incubation in monolayer aortic ECs. Caveolae mediates transportation of LDL and other macromolecules to the subendothelial space, and inhibition of caveolae ameliorated the hyperpermeability induced by high glucose in the present study, which suggested that the high-glucose-induced hyperpermeability is mediated by caveolae in ECs. RSV down-regulated the VEGF, KDR, and cav-1 expressions simultaneously along with the alleviation of hyperpermeability, while selective inhibition of KDR down-regulated cav-1 expression and ameliorated the hyperpermeability. Thus, it appears that VEGF/KDR pathway is an upper stream regulator of caveolae. These result suggested that RSV ameliorated the caveolae-mediated hyperpermeability induced by high glucose via VEGF/KDR pathway. Further evidence of caveolin-mediated loss and gain function along with hyperpermeability will lead to a better understanding of the mechanisms.

Acknowledgments This work was supported by the National Key Technology R\&D Program of the People's Republic of China (No. 2008BAI58B00), National Natural Science Foundation of China (Grant No. 30972473, 81030051, 81172674), and Natural Science Foundation of Zhejiang Province (No.Y2100005, X. Ye). We are deeply indebted to Dr. H. Wu for her many helpful suggestions.

Conflicts of interest There are no conflicts of interest.

\section{References}

Alex D, Leong EC, Zhang ZJ, Yan GT, Cheng SH, Leong CW, Li ZH, Lam KH, Chan SW, Lee SM (2010) Resveratrol derivative, trans-3,5,4'-trimethoxystilbene, exerts antiangiogenic and vascular-disrupting effects in zebrafish through the downregulation of VEGFR2 and cell-cycle modulation. J Cell Biochem 109(2):339-346

Argaw AT, Gurfein BT, Zhang Y, Zameer A, John GR (2009) VEGFmediated disruption of endothelial CLN-5 promotes blood-brain barrier breakdown. Proc Natl Acad Sci USA 106(6):1977-1982

Auger C, Teissedre PL, Gérain P, Lequeux N, Bornet A, Serisier S, Besançon P, Caporiccio B, Cristol JP, Rouanet JM (2005) 
Dietary wine phenolics catechin, quercetin, and resveratrol efficiently protect hypercholesterolemic hamsters against aortic fatty streak accumulation. J Agric Food Chem 53(6):2015-2021

Bates DO, Harper SJ (2002) Regulation of vascular permeability by vascular endothelial growth factors. Vascul Pharmacol 39(4-5): 225-237

Blann AD, Belgore FM, McCollum CN, Silverman S, Lip PL, Lip GY (2002) Vascular endothelial growth factor and its receptor, Flt-1, in the plasma of patients with coronary or peripheral atherosclerosis, or Type II diabetes. Clin Sci (Lond) 102(2):187-194

Chen J, Braet F, Brodsky S, Weinstein T, Romanov V, Noiri E, Goligorsky MS (2002) VEGF-induced mobilization of caveolae and increase in permeability of endothelial cells. Am J Physiol Cell Physiol 282(5):C1053-C1063

Chu LM, Robich MP, Lassaletta AD, Feng J, Laham RJ, Burgess T, Clements RT, Sellke FW (2011) Resveratrol supplementation abrogates pro-arteriogenic effects of intramyocardial vascular endothelial growth factor in a hypercholesterolemic swine model of chronic ischemia. Surgery 150(3):390-399

Cukiernik M, Hileeto D, Evans T, Mukherjee S, Downey D, Chakrabarti S (2004) Vascular endothelial growth factor in diabetes induced early retinal abnormalities. Diabetes Res Clin Pract 65(3): 197-208

Dang L, Seale JP, Qu X (2005) High glucose-induced human umbilical vein endothelial cell hyperpermeability is dependent on protein kinase $\mathrm{C}$ activation and independent of the $\mathrm{Ca} 2+-$ nitric oxide signalling pathway. Clin Exp Pharmacol Physiol 32(9):771-776

DeMaio L, Antonetti DA, Scaduto RC Jr, Gardner TW, Tarbell JM (2004) VEGF increases paracellular transport without altering the solvent-drag reflection coefficient. Microvasc Res 68(3):295-302

Drab M, Verkade P, Elger M, Kasper M, Lohn M, Lauterbach B, Menne J, Lindschau C, Mende F, Luft FC, Schedl A, Haller H, Kurzchalia TV (2001) Loss of caveolae, vascular dysfunction, and pulmonary defects in caveolin-1 gene-disrupted mice. Science 293:2449-2452

Dugas B, Charbonnier S, Baarine M, Ragot K, Delmas D, Menetrier F, Lherminier J, Malvitte L, Khalfaoui T, Bron A, Creuzot-Garcher C, Latruffe N, Lizard G (2010) Effects of oxysterols on cell viability, inflammatory cytokines, VEGF, and reactive oxygen species production on human retinal cells: cytoprotective effects and prevention of VEGF secretion by resveratrol. Eur J Nutr 49(7):435-446

Elcioglu KH, Kabasakal L, Cetinel S, Conturk G, Sezen SF, Ayanoglu-Dulger G (2010) Changes in caveolin-1 expression and vasoreactivity in the aorta and corpus cavernosum of fructose and streptozotocin-induced diabetic rats. Eur J Pharmacol 642(1-3): 113-120

Fan E, Zhang L, Jiang S, Bai Y (2008) Beneficial effects of resveratrol on atherosclerosis. J Med Food 11(4):610-614

Feng Y, Venema VJ, Venema RC, Tsai N, Behzadian MA, Caldwell RB (1999) VEGF-induced permeability increase is mediated by caveolae. Invest Ophthalmol Vis Sci 40(1):157-167

Fernandez-Hernando C, Yu J, Suarez Y, Rahner C, Davalos A, Lasuncion MA, Sessa WC (2009) Genetic evidence supporting a critical role of endothelial caveolin-1 during the progression of atherosclerosis. Cell Metab 10(1):48-54

Fernandez-Hernando C, Yu J, Davalos A, Prendergast J, Sessa WC (2010) Endothelial-specific overexpression of caveolin-1 accelerates atherosclerosis in apolipoprotein E-deficient mice. Am J Pathol 177(2):998-1003

Frank PG, Lee H, Park DS, Tandon NN, Scherer PE, Lisanti MP (2004) Genetic ablation of caveolin-1 confers protection against atherosclerosis. Arterioscler Thromb Vasc Biol 24(1):98-105

Gustafsson M, Boren J (2004) Mechanism of lipoprotein retention by the extracellular matrix. Curr Opin Lipidol 15(5):505-514
Holmes K, Roberts OL, Thomas AM, Cross MJ (2007) Vascular endothelial growth factor receptor-2: structure, function, intracellular signalling and therapeutic inhibition. Cell Signal 19(10):2003-2012

Hordijk PL, Anthony E, Mul FP, Rientsma R, Oomen LC, Roos D (1999) Vascular endothelial cadherin modulates endothelial monolayer permeability. J Cell Sci 112:1915-1923

Hoshi S, Nomoto K, Kuromitsu J, Tomari S, Nagata M (2002) High glucose induced VEGF expression via PKC and ERK in glomerular podocytes. Biochem Biophys Res Commun 290(1):177-184

Kim NH, Jung HH, Cha DR, Choi DS (2000) Expression of vascular endothelial growth factor in response to high glucose in rat mesangial cells. J Endocrinol 165(3):617-624

Kim YH, Kim YS, Roh GS, Choi WS, Cho GJ (2012) Resveratrol blocks diabetes-induced early vascular lesions and vascular endothelial growth factor induction in mouse retinas. Acta Ophthalmol 90(1):e31-e37

Klein U, Gimpl G, Fahrenholz F (1995) Alteration of the myometrial plasma membrane cholesterol content with $\beta$-cyclodextrin modulates the binding affinity of the oxytocin receptor. Biochemistry 34:13784-13793

Komarova Y, Malik AB (2010) Regulation of endothelial permeability via paracellular and transcellular transport pathways. Annu Rev Physiol 72:463-493

Kopp P (1998) Resveratrol, a phytoestrogen found in red wine. A possible explanation for the conundrum of the 'French paradox'? Eur J Endocrinol 138(6):619-620

Laakso M (1999) Hyperglycemia and cardiovascular disease in type 2 diabetes. Diabetes 48(5):937-942

Laakso M (2008) Cardiovascular disease in type 2 diabetes from population to man to mechanisms: the Kelly west award lecture. Diabetes Care 33(2):442-449

Lin YL, Chang HC, Chen TL, Chang JH, Chiu WT, Lin JW, Chen RM (2010) Resveratrol protects against oxidized LDL-induced breakage of the blood-brain barrier by lessening disruption of tight junctions and apoptotic insults to mouse cerebrovascular endothelial cells. J Nutr 140(12):2187-2192

Low B, Liang M, Fu J (2007) p38 mitogen-activated protein kinase mediates sidestream cigarette smoke-induced endothelial permeability. J Pharmacol Sci 104(3):225-231

Michel CC, Curry FE (1999) Microvascular permeability. Physiol Rev 79:703-761

Minshall RD, Tiruppathi C, Vogel SM, Niles WD, Gilchrist A, Hamm HE, Malik AB (2000) Endothelial cell-surface gp60 activates vesicle formation and trafficking via G(i)-coupled Src kinase signaling pathway. J Cell Biol 150:1057-1070

Nunez MJ, Novio S, Balboa J, Seoane J, Suarez JA, Freire-Garabal M (2010) Effects of resveratrol on expression of vascular endothelial growth factor in human gingival fibroblasts stimulated by periodontal pathogens. Acta Odontol Scand 68(4):239-247

Parpal S, Karlsson M, Thorn H, Stralfors P (2001) Cholesterol depletion disrupts caveolae and insulin receptor signaling for metabolic control via insulin receptor substrate-1, but not for mitogen-activated protein kinase control. J Biol Chem 276(13): 9670-9678

Pavlides S, Gutierrez-Pajares JL, Danilo C, Lisanti MP, Frank PG (2012) Atherosclerosis, caveolae and caveolin-1. Adv Exp Med Biol 729:127-144

Scalia R, Gong Y, Berzins B, Zhao LJ, Sharma K (2007) Hyperglycemia is a major determinant of albumin permeability in diabetic microcirculation: the role of mu-calpain. Diabetes 56(7): $1842-1849$

Senger DR, Connolly DT, Van de Water L, Feder J, Dvorak HF (1990) Purification and NH2-terminal amino acid sequence of guinea pig tumor-secreted vascular permeability factor. Cancer Res 50(6):1774-1778 
Simionescu M (2007) Implications of early structural-functional changes in the endothelium for vascular disease. Arterioscler Thromb Vasc Biol 27(2):266-274

Sone H, Kawakami Y, Okuda Y, Kondo S, Hanatani M, Suzuki H, Yamashita K (1996) Vascular endothelial growth factor is induced by long-term high glucose concentration and upregulated by acute glucose deprivation in cultured bovine retinal pigmented epithelial cells. Biochem Biophys Res Commun 221(1): 193-198

Sun SW, Zu XY, Tuo QH, Chen LX, Lei XY, Li K, Tang CK, Liao DF (2010) Caveolae and caveolin-1 mediate endocytosis and transcytosis of oxidized low density lipoprotein in endothelial cells. Acta Pharmacol Sin 31(10):1336-1342

Szmitko PE, Verma S (2005) Cardiology patient pages. Red wine and your heart. Circulation 111(2): e10-e11

Webster MW, Scott RS (1997) What cardiologists need to know about diabetes. Lancet 350 Suppl 1:SI23-SI28

Yang N, Ying C, Xu M, Zuo X, Ye X, Liu L, Nara Y, Sun X (2007) High-fat diet up-regulates caveolin-1 expression in aorta of dietinduced obese but not in diet-resistant rats. Cardiovasc Res 76(1):167-174

Yang W, Lu J, Weng J, Jia W, Ji L, Xiao J, Shan Z, Liu J, Tian H, Ji Q, Zhu D, Ge J, Lin L, Chen L, Guo X, Zhao Z, Li Q, Zhou Z, Shan G, He J (2010) Prevalence of diabetes among men and women in China. N Engl J Med 362(12):1090-1101
Ying CJ, Xu JW, Ikeda K, Takahashi K, Nara Y, Yamori Y (2003) Tea polyphenols regulate nicotinamide adenine dinucleotide phosphate oxidase subunit expression and ameliorate angiotensin II-induced hyperpermeability in endothelial cells. Hypertens Res 26(10):823-828

Zamora-Ros R, Andres-Lacueva C, Lamuela-Raventos RM, Berenguer T, Jakszyn $\mathrm{P}$, Martinez C, Sanchez MJ, Navarro C, Chirlaque MD, Tormo MJ, Quiros JR, Amiano P, Dorronsoro M, Larranaga N, Barricarte A, Ardanaz E, Gonzalez CA (2008) Concentrations of resveratrol and derivatives in foods and estimation of dietary intake in a Spanish population: European prospective investigation into cancer and nutrition (EPIC)-Spain cohort. Br J Nutr 100(1):188-196

Zhang Q, Tang X, Lu QY, Zhang ZF, Brown J, Le AD (2005) Resveratrol inhibits hypoxia-induced accumulation of hypoxiainducible factor-1alpha and VEGF expression in human tongue squamous cell carcinoma and hepatoma cells. Mol Cancer Ther 4(10):1465-1474

Zhao LN, Yang ZH, Liu YH, Ying HQ, Zhang H, Xue YX (2011) Vascular endothelial growth factor increases permeability of the blood-tumor barrier via caveolae-mediated transcellular pathway. J Mol Neurosci 44(2):122-129 